\title{
Saúde do Trabalhador - Identidade dos Sujeitos e Representações dos Riscos a Saúde na Indústria Petroquímica
} Workers' Health - Subjects' Identity and Representations of Health Risks in the Petrochemical Industry

\author{
Maria Ligia Range ${ }^{1}$ \\ RANGEL, M. L. Workers' Health - Subjects' Identity and Representations of Health Risks in \\ the Petrochemical Industry. Cad. Saúde Públ., Rio de Janeiro, 9 (3): 333-348, jul/sep, 1993. \\ This study focuses on the importance of socio-cultural identity for establishing representations \\ concerning occupational risks existing at the workplace. Risks like social-cultural phenomena \\ which are socially constructed by subjects with various identities are discussed. The study \\ presents the results developed at a petrochemical industry in Camaçari, Bahia, Brazil. The \\ research studied the various ways that representations of occupational risks occur among \\ operations, maintenance and laboratory workers.
}

Key words: Occupational Health; Social Representations and Health; Petrochemical Workers' Health; Identity and Health

\section{INTRODUÇÃO}

O estudo que apresentamos foi realizado nos anos de 1990 e 1991 , período em que as questões de saúde evidenciavam-se no Pólo Petroquímico de Camaçari-Ba, através do crescimento de casos de acidentes de trabalho, doenças ocupacionais e das subseqüentes denúncias por parte do sindicato dos trabalhadores e da imprensa local.

A indústria petroquímica é pioneira, não só em processos de trabalho automatizados, como também inova os riscos à saúde nos locais de trabalho. O trabalho é feito, necessariamente, em turnos, incluindo o noturno, por equipes de trabalhadores que se revezam, vivendo um cotidiano repleto de incertezas e expostos a uma gama variada de substâncias químicas. É um coletivo predominantemente masculino, dotado de predicados requeridos por esse tipo de empresa, e que são tradicionalmente atribuídos a este sexo - responsabilidade, audácia, virilidade (Hirata, 1984).

${ }^{1}$ Programa de Saúde do Trabalhador da Secretaria Municipal de Saúde de Campinas. Avenida Anchieta 200, $11^{\circ}$ andar, Campinas, SP, 13015-100, Brasil.
O estudo das práticas e representações, conformadas em torno dos riscos por esses sujeitos, pressupõe o exame do conceito de identidade. Isso porque a análise deste último nos possibilita entender a multiplicidade de formas com que indivíduos ou grupos sociais se relacionam com os riscos nos locais de trabalho, uma vez que a identidade está ligada, firmemente, à capacidade de perceber e construir diferenças no mundo social, resultando em práticas e representações sociais distintas.

Para desenvolver o conceito de identidade, duas premissas colocadas por Berger \& Luckman (1976:228), parecem encontrar eco nas formulações de outros autores, em torno dessa categoria. A primeira premissa é a de que a identidade é formada em processos sociais. A segunda, de que a teorização sobre ela tem que se fazer no quadro de interpretações em que estão localizadas.

A tradição teórica marxista que trata a questão da identidade, remetendo-a à noção de classe social, tem sido alvo de críticas no seio da sociologia. Esta, por aproximação com outras disciplinas como a psicologia e a antropologia, tem-se preocupado em redefinir esse conceito, rompendo com a noção reificada de 
classe, como argumentam Knights \& Willmott (1989). Esses autores e outros como Bourdieu (1988), têm realizado estudos promissores no sentido de resgatar a dimensão subjetiva do mundo percebido, ao lado da sua estruturação objetiva mais tradicionalmente desenvolvida por autores marxistas.

A partir da reflexão desses autores, a dimensão da ideologia ganha novos contornos, deixando de constituir meros reflexos de um mundo objetivado, para se construir a partir de sujeitos concretos, individuais e coletivos.

A identidade social, segundo Sainsaulieu (s/d), é construída a partir de um processo complexo de aprendizagem cultural, que é mais do que um mecanismo de transmissão ou inculcação de normas e valores. Isso porque estão em jogo processos microssociais e sócio-psicológicos de adesão aos valores recebidos, ou de criação de novos valores. Para esse autor, a identidade social está profundamente ligada ao tipo de cultura que o indivíduo constitui como um capital progressivo de relação entre experiências desenvolvidas no tempo e no espaço. A identidade seria, assim, um modo mental que se dispõe para perceber o idêntico e o diferente na diversidade dos engajamentos dos sujeitos (Sainsaulieu, s/d:283).

A construção da identidade é, como mostra Sainsaulieu (s/d:282), uma dinâmica relacional de produção cultural em que o indivíduo reconhece a si mesmo pelo que é idêntico e o que é diferente, nas suas experiências, tendo por referência o outro, numa relação de poder.

Identidade, poder e cultura encontram-se intimamente imbricados, pois que a identidade se recoloca sobre uma cultura de imagens e representações fortemente articuladas entre si e simbolizadas por ricas relações (Sainsaulieu, s/d), mediadas pelas lutas de poder. A luta pelo poder, diz Sainsaulieu, não é um fim em si, mas um sinal social de um jogo mais profundo da personalidade, que se insere no coração de toda relação prolongada (Sainsaulieu, 1977:333).

Em Sainsaulieu, vamos encontrar a idéia de interiorização, ao nível do indivíduo, das ligações culturais de si consigo mesmo, sob a forma de estruturas mentais, de normas e escalas de valores (Sainsaulieu, s/d:283). Tais aspectos conformam os modelos culturais que geram relações de representações e ações, sendo elas mesmas conseqüências de dificuldades sociais complexas e repetitivas dentro das quais os atores não podem evitar de viver se quiserem permanecer em sociedade (op. cit:279).

Em Bourdieu (1988), encontramos idéia semelhante, de que a identidade social supõe a existência de uma matriz de percepção, apreciação e ação, que ele chama de habitus.

Os esquemas de habitus são, para Bourdieu, formas de classificação originárias, que devem sua eficácia própria ao fato de que funcionam além da consciência e do discurso; logo, fora das influências do exame e do controle voluntário. De tal modo que orienta as práticas e esconde valores nos gestos mais automáticos, nas técnicas do corpo mais insignificantes na aparência, como os movimentos das mãos ou as maneiras de andar, de sentar, de dormir ou de falar. Oferecem os princípios mais fundamentais da construção da avaliação do mundo social (Bourdieu, op. cit:477).

Para o referido autor, é por meio da internalização desses complexos processos sócio-psicológicos que se define a eficácia ideológica, pela remissão às oposições mais fundamentais à ordem social. A construção da identidade no trabalho se fará, portanto, com base na identidade, conformada pelos sujeitos no seu contexto das relações de poder nos locais de trabalho, tendo por base o habitus construído dentro e fora dele.

Sainsaulieu ainda alerta para as dificuldades da construção da identidade no trabalho, face às múltiplas crises que abalam uma definição sócio-profissional da identidade, seja nos seus sistemas de retribuição (salário, segurança, promoção e consideração que deixam de ter efeitos de motivação), seja pelas formas de organização do trabalho que requerem mudanças de papéis e das práticas autoritárias; seja, ainda, no domínio sindical em que seu reconhecimento e poder de negociação colocam em pauta contestações e reivindicações. Para Sainsaulieu, existe uma dissonância entre as circunstâncias de ação e as representações sociais das relações na organização, que dificulta a construção da identidade no trabalho (op. cit:277).

Knights \& Willmott, ao estabelecerem o nexo entre poder, subjetividade e identidade, enfocam os temas de controle e resistência no trabalho. 
Calcados no pensamento de Foucault, eles salientam "how subjects come to recognise themselves as discrete and autonomous individual whose sense of a clear identity is sustained through participation in social practices which are a condition and consequence of the exercise of power and the production of specific knowledges" (Knights \& Willmott, 1989:538).

A proposta de Knights \& Willmott é elaborar uma teoria da subjetividade, desenhada a partir das críticas ao jovem Marx, concentrando sobre as relações entre poder e subjetividade, prestando especial atenção aos temas do controle e resistência.

Esses autores reconhecem na relação poder-conhecimento, poder-saber, uma instância definidora dos reais interesses dos sujeitos e propoem que os trabalhadores sejam pensados não como força de trabalho, mas como indivíduos, que são totalidades, que pensam, sentem, aspiram, constroem imagens e representações. Para tanto, importam seus processos inconscientes, suas experiências dentro e fora do trabalho, pretéritas, não só as presentes e racionalizadas e a partir das quais constroem sua ação individual e coletiva.

Com base nesses pressupostos teóricos, pode-se supor que é a partir da construção de sua subjetividade e identidade no trabalho que os trabalhadores constroem, também, as suas representações de riscos e, sobre elas, desenvolvem um saber específico, como parte de seu capital cultural. Importam, assim, as suas experiências anteriores com riscos e os significados que estes assumem em diferentes contextos de trabalho, no interior das relações de poder que se tecem nos distintos locais de trabalho e conformam culturas do risco peculiares.

Assim, as diferenças sócio-culturais dos atores, expressas na sua identidade e subjetividade, estão implicadas nas relações de poder nos locais de trabalho e, por essa via, definem as distintas representações do risco.

Agier \& Guimarães (1990), estudando a identidade dos trabalhadores do Pólo Petroquímico de Camaçari-Ba, se depararam com uma identidade construída em conflito e com representações de trabalho heterogêneas ou mesmo contraditórias.

Os autores mostram que os projetos pessoais de ascensão social, forjados no seio da família, se adequam à figura dominante da indústria de processo, constituindo uma identidade social voltada para a profissão e para a inserção na "coletividade industrial". Porém, as experiências concretas do cotidiano das relações no espaço fabril levam à construção de uma identidade no trabalho em conflito. Isso porque a formação do técnico forja uma construção da profissão como moderna, portadora de um ideário futurista, útil, prática, produtiva, que a contrasta com a tradição bacharelesca e "doutoresca" das universidades, que produzem um conhecimento dito "inútil", "improdutivo" e "poético", mas inatingível para a maioria dos trabalhadores. Por outro lado, esses trabalhadores vivenciam relações no trabalho que os levam a referir-se a si próprios como "peões", como forma simbólica de insubordinação. Agier \& Guimarães (1990) identificam entre esses trabalhadores (os operadores), dois tipos de interpelações ideológicas: a ideologia do desempenho e a ideologia da segurança. Os autores observam que à apresentação dos indivíduos no mercado de trabalho, estes já são dotados de valores em relação ao trabalho, ao saber, ao dinheiro e de meios de barganha tais como formação escolar, diplomas, capital cultural etc, adquiridos nas linhas familiares e pela atuação da família de origem. No presente trabalho, pretende-se examinar como tal constituição da identidade dos trabalhadores petroquímicos participam da construção das representações sociais, conformadas em torno dos riscos à saúde nos locais de trabalho.

\section{METODOLOGIA}

Considerou-se neste estudo que o risco se constrói, socialmente, e se define pelo seu oposto - a segurança - e, ainda, que a representação do risco se faz, pelos sujeitos vivendo relações de poder no cotidiano fabril. Valorizou-se a relação construída entre a forma de reconhecimento do risco e o significado que lhe é conferido e à tecnologia de segurança - nela incluídas as normas, equipamentos e procedimentos de segurança - para a realização do trabalho. Valorizou-se para a análise a história 
profissional e origem sócio-cultural dos sujeitos, bem como sua inserção no processo de trabalho e forma de acesso ao cargo ou função.

A indústria petroquímica é definida, basicamente, em função das matérias-primas que utiliza, oriundas do petróleo e gás natural. Os insumos e produtos são, geralmente, gases ou líquidos em trocas sucessivas de seus estados físicos. São, freqüentemente, altamente corrosivos, inflamáveis, explosivos e tóxicos. Tais características dos insumos e produtos impõem a utilização de um processo de transformação do tipo fluxo contínuo, ininterrupto, hermético, em que as reações se dão no interior dos equipamentos por onde circulam as substâncias. Tais indústrias são, por isso, pioneiras em matéria de automação. É também uma indústria altamente intensiva em capital, investindo mais em tecnologia automatizada e integrada e poupadora de mão-de-obra.

O trabalho humano nesse tipo de indústria é, prioritariamente, voltado para a vigilância do processo, das condições necessárias para que ocorram as transformações físico-químicas desejadas, com o menor risco de perdas de insumos e produtos e o menor desgaste para os equipamentos.

Embora o processo produtivo seja contínuo, eventualmente ocorrem interrupções, via de regra, programadas com o objetivo de fazer a manutenção dos equipamentos.

A empresa estudada é uma petroquímica de segunda geração, de capital misto, com três principais acionistas: a Petrobrás Química S/A - Petroquisa, uma holding subsidiária da Petrobrás que detém 33\% das ações; a Rhodia S/A, uma empresa privada nacional com controle estrangeiro, detém $26 \%$ das ações e a Unigel Participações Serviços Industriais Ltda, detém 4\% das ações. Trata-se de uma empresa de médio porte com 347 trabalhadores, instalada no II Pólo Petroquímico Brasileiro, em Camaçari-Ba, desde 1976. Este representa, para a região, um fator de mudança significativa na oferta de empregos, com a geração de um novo operariado com características peculiares (Agier \& Castro, 1989) e com impacto não só na economia regional, mas, também, na nacional (Guimarães \& Castro, 1988). São hoje cerca de 50 mil trabalhadores, dos quais $50 \%$ são subcontratados, empregados num complexo indus- trial, cuja produção é integrada e interdependente, sustentado por um modelo tripartite do qual participam de modo igualitário o Estado (através da Petroquisa), empresas nacionais e multinacionais. Embora com gestão unificada, através de três órgãos (o Cofic - Comitê de Fomento Industrial de Camaçari; o Sinper Sindicato da Indústria Petroquímica e o Divin - Divisão de Informação da Petrobrás), podese observar peculiaridades na gestão a depender do porte e das características particulares do processo de trabalho.

As atividades básicas da indústria petroquímica requerem três tipos de trabalhadores, atuando junto ao processo de transformação: os operadores, os analistas de laboratório e os mantenedores. Além destes, técnicos de segurança do trabalho, acompanham o desenvolvimento das tarefas. Um setor administrativo, geralmente com contingente numericamente semelhante ao de produção, dá suporte às atividades.

Devido à especificidade de seu processo produtivo, esse tipo de indústria apresenta um modelo gerencial peculiar. A produtividade não depende do trabalhador individual, mas da sintonia das equipes de trabalho que se alternam em turnos, aliada à capacidade nominal da planta, ao grau de eficiência dos equipamentos e do funcionamento ininterrupto do processo (Guimarães, 1990:106). Expostos a um conjunto de situações de risco, os trabalhadores, em última instância, acabam por consentir, de algum modo, o trabalho sob risco em troca dos benefícios que as empresas oferecem.

Essas características do processo de trabalho requerem dos trabalhadores um alto nível de qualificação, responsabilidade, cooperação e confiabilidade, que conferem ao modelo gerencial aspectos singulares. Ressalta-se a existência de um savoir-faire que é desenvolvido pelos trabalhadores, que complementa o saber técnico adquirido nas escolas e que se torna indispensável para que o sistema técnico funcione (Terssac \& Coriat, 1984:388).

A necessidade de se estabelecer uma relação cooperativa e de confiança, dificulta relações de caráter despótico, conformando-se políticas de gestão de cunho predominantemente paternalistas. Nesse sentido, observa-se na empresa estudada um modelo de gestão que segue o do Pólo, mas que acentua o traço paternalista 
através do discurso de "grande família". Contudo, o exercício do controle do trabalho pela gerência se faz com o uso de mecanismos autoritários, na forma de "castigos" ou "punições", caracterizando relações do tipo paternalista despótico.

A concentração do saber e do poder encontrase nas mãos de poucos - os gerentes e os operadores de painel. Os demais desenvolvem, via de regra, algum tipo de esforço para alcançar essas posições. Contudo o que predomina na empresa, tanto entre as chefias e cargos de maior concentração de poder, como entre os chamados "peões", é o descrédito nessa "grande família", cujas condições de trabalho e do mercado de mão de obra acentua a competitividade e, sobretudo, a desilusão com as possibilidades de ascensão social.

O trabalhador petroquímico é um coletivo predominantemente do sexo masculino, de escolaridade média ou superior. Recebem formação técnico-científica em escolas técnicas, que formam especialistas em conhecimento aplicado e no conhecimento dos "meios" instrumentais relativos a certas áreas práticas da ciência (eletricidade, mecânica, análise química, processos petroquímicos, instrumentação etc) (Agier \& Guimarães, 1990). É um tipo de trabalhador incentivado à responsabilidade, ao autocontrole , cuja cultura do trabalho envolve fortemente noções de perigo. Esses trabalhadores constroem um código ético-cultural, moldado pela equipe de trabalho, que define valores tais como confiança em si e nos outros, competência, coragem, responsabilidade consigo, com os outros e com os equipamentos.

A empresa estudada possui um quadro de trabalhadores relativamente estável, tendo recrutado a maioria de sua força de trabalho, em 1978, num mercado que oferecia uma mãode-obra qualificada escassa, tendo que capacitar seu corpo técnico no sul do país ou mesmo no exterior. Contudo, não é essa a realidade dos anos em que transcorreu a pesquisa. $\mathrm{O}$ contexto da pesquisa é aquele em que se observa oferta significativa de mão-de-obra qualificada no mercado, aliada à crise sócio-econômica que se aprofundou com o Plano Collor. Esta se refletiu no Pólo com uma onda de paradas de manutenção e um crescente descontentamento do operariado pela perda progressiva do seu poder aquisitivo, já em curso há alguns anos, aliado às ameaças de demissão. Como parte desse contexto sobressaíam as denúncias freqüentes, na imprensa local e nacional, dos problemas de saúde dos trabalhadores, especialmente dos acidentes graves e fatais e da leucopenia que acometiam numerosos trabalhadores do Pólo.

A pesquisa foi realizada ao longo dos anos de 1990 e 1991, quando foi obtido o consentimento da empresa para observar o processo de trabalho, estudar o processo produtivo e os riscos nele implicados e entrevistar os trabalhadores.

Foram realizadas 42 entrevistas, orientadas por um roteiro flexível com trabalhadores dos diferentes setores: operação, manutenção e laboratório, que representaram 25\% dos trabalhadores do setor de produção da empresa, excluídos aqueles do setor administrativo. Foram, também, realizadas várias entrevistas não-estruturadas, durante o período de observação do processo de trabalho.

As entrevistas buscavam obter informações que caracterizassem a identidade sócio-cultural dos sujeitos, enfocasse as suas experiências com acidentes, doença e morte no trabalho, bem como suas representações de trabalho, risco, segurança e saúde.

Os encontros se deram no interior da empresa, onde obtivemos o consentimento para realizar as entrevistas com liberação dos trabalhadores. Não tendo sido possível gravar as falas, estas foram registadas imediatamente e seguidas de um relato minuncioso das impressões que ficavam à entrevistadora. Os dados foram, em seguida, organizados, segundo a inserção dos trabalhadores na empresa, observando-se os traços de sua identidade sócio-cultural, suas formas de identificar os riscos existentes no cotidiano de trabalho e suas formas de representá-los.

Face às dificuldades teóricas de definir formas de operacionalização do conceito de identidade e, tendo como pano de fundo os estudos realizados por Agier \& Castro (1989) e Agier \& Guimarães (1990) em torno da identidade do trabalhador petroquímico, optou-se por identificar suas diferenciações na empresa, considerando aspectos do seu capital sócio-cultural tais como: idade, sexo, início na vida laborativa, história profissional, tempo de serviço, bairro 
residencial, profissão do pai, forma de ingresso na empresa e escolaridade.

Procurou-se, assim, identificar as formas de reconhecimento do risco entre os trabalhadores entrevistados, a valorização que é conferida à tecnologia de segurança, na sua relação com o trabalho e os jogos de poder nele existentes. Levou-se em conta que o risco, como entidade liminar, é suscetível a uma definição subjetiva, e, pelo seu caráter virtual, é permeável à relação de poder/saber na sua construção social.

Foram identificadas três tendências básicas no discurso do reconhecimento do risco: a) negação do risco - manifesta na afirmativa do sujeito de que não há risco no trabalho; b) eufemização ou relativização do risco, manifesta na afirmativa do sujeito de que há risco no trabalho. Mas, afirmando, logo em seguida, que ele é controlado e neutralizado de algum modo: pela tecnologia de segurança; pela localização geográfica da empresa; pela generalização do risco à vida, naturalizado-o; pela remissão do risco do passado ou para fora da empresa; c) ênfase do risco, expressa na afirmativa, veemente, de que há risco no trabalho, evidenciada pelo uso de adjetivos aumentativos e/ou pela dificuldade de identificar locais de proteção. Nesse caso, os riscos são vistos em todos os lugares, dentro e fora da fábrica, podendo-se precisar atividades e locais de maior risco, embora com dificuldades para identificar os de menor risco.

Para compreender as representações do risco, lançou-se mão da representação do trabalho entre os entrevistados, como elemento definidor das representações dos sujeitos. Foram identificadas cinco formas de representar o trabalho:

1.Valorização do saber necessário à função, evidenciando satisfação ou realização pessoal com o trabalho e tomando o saber como fonte de autovalorização. A insatisfação é menor e se manifesta pela existência de certos limites ao saber que a empresa impõe. Pode-se acompanhar de um sentimento de orgulho ou simples aceitação das condições de trabalho. Geralmente, o trabalhador é imbuído do espírito de colaboração requerido pela empresa. Essa forma esteve presente em $83 \%$ dos analistas, $37,5 \%$ dos operadores e $11,5 \%$ dos mantenedores.
2. Valorização do saber necessário à função, porém demonstrando insatisfação com o trabalho, especialmente devido aos baixos salários atuais e as condições de trabalho. Revelação de certo desencanto e/ou aprisionamento com o trabalho ou mesmo revolta com a condição em que o trabalhador se encontra. Foi encontrada em 17\% dos analistas entrevistados, $12,5 \%$ dos operadores e $5,5 \%$ dos mantenedores.

3. Ênfase às normas como saberes e benefícios que apóiam a realização do trabalho ou certo conformismo, pois o trabalho não satisfaz, mas é necessário. Encontrou-se em 6,25\% dos operadores e $29,41 \%$ dos mantenedores.

4. Valorização do esforço físico e mental e do desgaste no trabalho, confrontando-se com os baixos salários e expressando uma forte insatisfação muitas vezes manifesta pelo desejo de sair do emprego, ao qual se sente de certa forma aprisionado, pela falta de alternativas. Encontrou-se em 37,5\% dos operadores e $29,41 \%$ dos mantenedores.

5. Valorização do esforço físico necessário ao trabalho e das exigências de cumprimento de normas, como forma de proteção e manifestação de certo agradecimento por ter alcançado o emprego ou a posição em que se encontra. Demonstra confiança na empresa e esperança de melhorar os salários e continuar ascendendo. Encontrada em 6,25\% dos operadores entrevistados e $23,5 \%$ dos mantenedores.

\section{FORMAS DE REPRESENTAÇÃO DO RISCO}

O reconhecimento do risco no trabalho petroquímico na indústria estudada, embora estivesse presente no discurso de todos os trabalhadores, apresentou matizes bastante distintas que iam desde a tendência a negar o risco até a enfatizálo com veemência.

A negação dos riscos foi encontrada apenas entre os mantenedores, estando presente nos discursos de três trabalhadores $(17,7 \%$ dos mantenedores entrevistados) e, mais enfaticamente, em um caso $(5,8 \%)$. A eufemização ou relativização do risco foi encontrada em $37,5 \%$ dos operadores, $47 \%$ dos mantenedores e $50 \%$ 
dos laboratoristas. A ênfase ao risco foi encontrada em $43,75 \%$ dos operadores, $23,5 \%$ dos mantenedores e $33,4 \%$ dos laboratoristas. Os demais trabalhadores apresentaram discursos não muito bem-definidos.

Em relação à tecnologia de segurança, foram identificadas duas tendências básicas no discurso dos trabalhadores: a) ênfase à tecnologia de segurança, manifesta na afirmativa de que a tecnologia de segurança (normas, equipamentos, procedimentos) são condições suficientes para manter os riscos sob controle e oferecer proteção no trabalho. Geralmente, a tecnologia de segurança era elogiada e havia confiabilidade total do sujeito na planta, na equipe e nos equipamentos, bem como valorização do trabalho da Cipa e das Brigadas; b) eufemização ou relativização da tecnologia de segurança, manifesta na afirmativa de que as normas são exageradas e apresentam orientações ou regras obsoletas ou que dificultam a execução do trabalho ou, ainda, que não cobrem todas as necessidades de segurança. Exigem, portanto, que o trabalhador use o "bom senso", para selecionar aquelas que são adequadas ao seu trabalho, e que formule outros procedimentos, de modo a garantir a sua proteção no trabalho. Havia reconhecimento dos limites que os equipamentos de segurança oferecem e críticas à generalização do seu uso.

A ênfase à tecnologia de segurança foi observada em $37,5 \%$ dos trabalhadores da operação entrevistados, 70,6\% dos mantenedores e $50 \%$ dos laboratoristas. A eufemização ou relativização da tecnologia de segurança foi identificada em $50 \%$ dos operadores, $29,4 \%$ dos mantenedores e $33,4 \%$ dos laboratoristas. Os demais apresentaram um discurso não muito definido.

Quando foram relacionadas as formas de reconhecimento do risco com as formas de se referir à tecnologia de segurança, encontrou-se quatro formas de representação do risco: a) relativização do risco com ênfase à tecnologia de segurança; b) ênfase ao risco com relativização da tecnologia de segurança; c) ênfase ao risco e ênfase à tecnologia de segurança e d) relativização do risco e relativização da tecnologia de segurança.

Dentre os operadores predominou a ênfase ao risco com relativização da tecnologia de segurança, enquanto entre os mantenedores predomi- nou a relativização do risco com ênfase à tecnologia de segurança. Entre os laboratoristas predominaram as duas primeiras formas descritas acima, que se apresentaram como as de maior freqüência.

Para exemplificar as representações dos riscos dos trabalhadores entrevistados, foram selecionados dois casos da operação, dois da manutenção e um do laboratório. Procurou-se, desse modo, contemplar algumas formas típicas de representação do risco que conformam eixos discursivos e suas respectivas representações do trabalho nos diferentes setores. Os casos serão apresentados de modo a propiciar a verificação das suas formas de representação do risco e trabalho, assim como as suas características pessoais que contribuem para a conformação de sua identidade.

\section{Divisão de Operação}

Trata-se de um contingente operário do sexo masculino, com idade máxima de 58 anos e mínima de 18 anos; $48 \%$ são maiores de 30 anos e 6,6\% têm mais de 20 anos. São oriundos da classe média da Bahia em 93,75\% dos casos e, mais raramente, de outros Estados $(6,25 \%)$. São geralmente filhos de funcionários públicos $(31,25 \%)$, de comerciários $(25 \%)$ ou de industriários $(18,75 \%)$. Um menor contingente da amostra é filho de motorista autônomo (12,5\%), e em menor proporção, filhos de lavrador $(6,25 \%)$ ou de profissional de nível universitário $(6,25 \%)$.

A amostra revelou que $37 \%$ dos operadores iniciaram a vida laborativa entre 10 e 14 anos de idade, $12,5 \%$ entre 15 e 17 anos e $50 \%$ com mais de 18 anos. $\mathrm{O}$ mais freqüente é que a atividade laborativa tenha ocorrido no setor de serviços nas funções de mensageiro, vendedor ambulante, auxiliar de serviços no comércio e na indústria; $18,75 \%$ dos operadores tiveram seu primeiro emprego na empresa estudada, enquanto $43,75 \%$ são provenientes do setor de comércio e $37,5 \%$ do setor industrial.

As formas de acesso dos operadores à empresa foram, em $62,50 \%$, na função de estagiário, $6,25 \%$ na função de office boy, 6,25\% na função de vigilante, $18,75 \%$ diretamente na função de operador I (operador de campo cargo inicial da carreira de operador) e $6,25 \%$ 
diretamente na função de operador III (operador de painel — penúltimo cargo na carreira de operador).

Dentre os 19 operadores que trabalham no controle do painel (operador III), $42 \%$ pertencem ao quadro inicial da empresa. Os demais foram sendo captados ao longo dos anos, numa proporção ascendente, até o ano de 1989.

Dentre os 15 operadores de campo tipo II, $26,66 \%$ são do quadro inicial. Os demais foram sendo captados com picos mais intensos nos anos de 82 e 84 , quando ingressaram $40 \%$ desse grupo.

Dentre os 24 operadores de campo do tipo I, a maioria $(75 \%)$ ingressou recentemente, entre os anos de 1988 e 1990 e apenas um (4,2\%) ingressou no início do funcionamento da empresa.

Os cargos de chefia, supervisão e operação de painel são, geralmente, ocupados por trabalhadores mais antigos, embora entre os operadores III alguns ingressaram nos últimos três anos que antecederam a pesquisa.

A observação da distribuição do saber/poder nesse setor revela a sua concentração na sala de controle, onde trabalham os operadores de painel, os operadores chefes e os engenheiros. Da sala de controle partem as decisões e a supervisão do conjunto do processo produtivo. Os operadores que trabalham no campo (área externa onde se distribuem os equipamentos) possuem um poder limitado, recebem ordens e orientações da sala de controle. Identificam-se, em parte, com os trabalhadores da manutenção, embora possuam um maior conhecimento do conjunto do processo produtivo.

Esse grupo se revela heterogêneo, enquanto identidades profissionais distintas, podendo ser reagrupados naqueles que trabalham na sala de controle, função privilegiada, e os que trabalham no campo (área externa onde operam os equipamentos e o processo de transformação das substâncias químicas) que possuem uma relação de subordinação maior. Embora sejam de origem sócio-cultural semelhante, os que alcançaram o trabalho na sala de controle o fizeram por se aproximaram mais do ideal estabelecido pela empresa, sejam eles trabalhadores novos ou antigos.

Esses trabalhadores, tanto quando enfatizam, como quando eufemizam os riscos, o fazem como forma de autovalorização no trabalho e mais raramente a ênfase se dá relacionando os riscos ao desgaste e revelando insatisfação com o trabalho. Assim vejamos alguns exemplos:

\section{A) Ênfase ao Risco com Ênfase à Tecnologia de Segurança e Autovalorização no Trabalho}

OA3 tem 31 anos, é procedente de Salvador, filho de funcionário público, iniciou a vida laborativa aos 18 anos de idade como mensageiro de jornal, durante um mês, seguindo-se um ano e meio num escritório de contabilidade e, em seguida, a empresa em estudo. Fez curso de contabilidade (segundo grau). Entrou na empresa como office boy e premaneceu nessa função por dois anos e meio, quando passou a trabalhar no setor de pessoal. Quatro anos depois, na vigência da greve de 1985, que resultou em várias demissões, recebeu estágio de três meses para se tornar operador. Durante quatro anos permaneceu como Operador I e atualmente é Operador II.

Para OA3 o risco é generalizado a tudo o que se faz, dependendo do indivíduo, e da situação, vinculado à idéia de ato inseguro, condição insegura e probabilidade:

\section{"risco normalmente é... tudo o que nós} fazemos tem um grau de risco alto ou baixo, mas a depender de cada situação... a mesma coisa que dirigir carro ou moto. Moto 95\% é morte. É sempre alta ou baixa a depender do que você está fazendo". (OA3-21)

Apesar de generalizar o risco, OA3 ao se reportar ao trabalho o enfatiza elegendo, imediatamente, seu ponto de preocupação com $o$ mesmo:

"aqui o que eu detesto, não gosto de trabalhar é com ácido sulfúrico. É o produto mais perigoso que tem, já aconteceu vários acidentes, comigo também (...) é um trabalho que requer muito cuidado. Só entra lá todo equipado, mas ninguém combina com ele". (OA3-26)

A atividade de menor risco para ele é condicionada ao uso de equipamento que, na sua opinião, possui a capacidade de neutralizar o risco: 
"Todo serviço tem um grau de risco. Retirada de amostra, o grau de risco é bem menor se você estiver equipado". (OA3-25)

Por outro lado, não consegue identificar local protegido na empresa:

"A gente que trabalha numa fábrica petroquímica, qualquer uma, é muito difícil saber se tá protegido ou não. A gente nunca sabe $o$ acidente quando vai acontecer. $O$ único lugar que tá seguro é em casa e assim mesmo, nem sempre..." (OA3-34)

A ênfase ao risco que aparece, eventualmente, em seu discurso se faz destacando a tecnologia de segurança, como um saber necessário e viabilizador do trabalho, e revelando submissão e conformismo no seu discurso, ao afirmar que os EPIS são incômodos, reportando-se à opinião dos outros, e aceitando o seu uso apesar de reconhecê-los como tal:

\section{“(...) Tem gente que acha que EPI é} incômodo, principalmente na retirada da amostra". (OA3-39)

"Eu uso, é incômodo mas tem que usar. É obrigatório e eu gosto de usar. Sol quente, usar macacão de PVC é incômodo, mas tem que ser usado, eu uso". (OA3-40)

Não demonstra necessidade ou desejo de participação ou colaboração quanto à elaboração de normas de segurança. Quando perguntamos se faria alguma proposta de mudança, demonstrou estar satisfeito com o que ocorre:

"O que nós fazemos é a reunião de segurança e nela vai eliminando isso aí... os riscos... cobram essas mudanças nas reuniões". (OA3-45)

Valoriza as normas de segurança como estão, mesmo que se depare com algumas dificuldades com elas. Demonstra certa cautela para afirmar que se sente tranqüilo com o trabalho na planta, especialmente porque considera "complexo" confiar na planta.

Valoriza, também, o saber e a inteligência como forma de se proteger dos riscos:

\section{"Tento enfrentar eles com cuidado e}

inteligência. Normalmente a gente trabalhando nessa fábrica, ou mesmo em casa, conhecendo o risco que tem, tem que fazer a coisa com cuidado". (OA3-30)

Refere-se ao trabalho, enfatizando o esforço de atenção, o cuidado e o saber, assim como os riscos presentes, e demonstrando satisfação com ele:

"Varia de turma prá turma (o trabalho), conheço todos os supervisores e operadores chefes. Procuro fazer meu serviço certo, sem falhar. Exige muita atenção, muito cuidado, já que trabalha com muitos produtos perigosos. Tem que saber o que tá fazendo, temos normas. Procuro sempre seguir as normas. Gosto do trabalho porque nunca é uma rotina, tem sempre uma coisa nova prá fazer.

Trabalhar com rotina para quem gosta do trabalho não deixa satisfeito". (OA3-13)

Ao valorizar o seu trabalho e a sua posição conquistada por uma rara oportunidade na empresa, OA3 tende a manter-se numa posição de aceitação de regras impostas, como que aguardando novas possibilidades de ascensão. Nesse caso, o risco parece ser representado como uma forma de valorização do trabalho, exigindo maior qualificação e conferindo-lhe maior poder social.

B) Ênfase ao Risco com Relativização da Tecnologia de Segurança, Ênfase ao Desgaste e Insatisfação Salarial no Trabalho

OC5 tem 26 anos, procedente de Salvador, filho de motorista autônomo, iniciou a vida laborativa aos 21 anos, sendo a empresa em estudo o seu primeiro emprego, onde ingressou há cinco anos como estagiário, tendo passado, após quatro meses, a Operador I.

OC5 enfatiza o risco que percebe no trabalho pela natureza das substâncias a que estão expostos.

Identifica atividades de maior risco, mas tem dificuldades para identificar as de menor risco. E só vê local protegido fora da área da produção.

"Pelo menos nas funções em que já trabalhei (o maior risco) aqui é encher os conteiner de 
HCN, porque o operador trabalha numa plataforma, apesar de estar todo equipado, mas só que se houver a ruptura de uma junta, algo que não possa ser sanado pelo operador na hora, vai contaminar a área toda". (OC5) "O momento do abastecimento é de grande risco para os outros que estão por perto". (OC5-24)

Quanto ao menor risco afirma:

"Não identifico, pode ter menor escala! Por exemplo: troca de bombas é simples, só exige atenção você fazer $o$ alinhamento correto $e$ meter o dedo na botoeira... mas existe o risco também... mas é bem menor... Na empresa como um todo não dá pra dizer..."(OC5-25)

OC5 manifesta desconfiança em relação à planta, aos companheiros de trabalho e aos equipamentos. Para ele, a proteção na empresa não existe, tal como representado em seu discurso:

"Confiar no que eu fiz, eu chequei. Se o cara diz: você pode começar a encher a carreta que a válvula lá de baixo tá fechada, eu só confio se eu vou lá e vejo fechada. Desconfiar de todo mundo..." (OC5-32)

"Não confio em informações passadas verbalmente. É bom não confiar. Escritas pelo menos você tá coberto. Confiar em Deus prá que tudo dê certo". (OC5-33)

Para OC5, não existem locais protegidos na empresa. Ele valoriza o conhecimento dos produtos envolvidos no processo produtivo, como forma de proteção, e aponta críticas a atividades da gerência que aumentam o risco e o desgaste no trabalho:

"Inadequado é sobrecarregar o operário. Por exemplo, eu soube um caso aqui recentemente na empresa que o operador tava dobrando turno. Ele entrou às 16 horas e sairia as 8 horas. Quando chegou pela manhã o muda dele atrasou a entrada e ele só saiu às 12 horas. Ficou 20 horas seguidas trabalhando aqui, e foi obrigado a efetuar a partida inclusive do HCN. A possibilidade de ser desatento em uma manobra ou outra foi muito grande". (OC5)
Valoriza os aspectos que produzem incômodo como o uso dos EPIs e aqueles que dificultam a execução do trabalho, mas afirma fazer uso deles "descuidando" de vez em quando.

"Na maioria dos casos (em que os trabalhadores não usam o EPI) é porque é incômodo. No trabalho em altura o cinto de segurança é obrigatório, mas eles tão deslocando e a cada espaço de um metro tem que modificar a posição dele, então você perde tempo, e já negligencia a segurança. Às vezes o cara não usa luva porque eles dizem que perde o tato". (OC5-39)

Valoriza o trabalho da brigada como forma de aprender a prestar socorro numa situação de emergência, e considera a Cipa atuante à medida em que leva, aos superiores, as situações de risco para tomarem medidas de segurança.

OC5 valoriza o trabalho pelos saberes que ele proporciona, esforço físico e mental e o desgaste no trabalho, confrontando-os com os baixos salários e expressando insatisfação relativa, vinculada ao salário e ao risco.

"O trabalho, aqui, exige muita atenção principalmente para execução de manobra, coleta de amostra. Há um desgaste pelo fato do turno, a modificação constante do horário de trabalho, e o operador é uma função para turno. A insatisfação é... eu não vou nem colocar a parte do salário, mas pela função que eu exerço é o risco ao qual nós estamos expostos e a remuneração por isso não condiz. Não vale a pena, como teria sido há algum tempo atrás, que foi a imagem que criaram na Escola Técnica... Ouvia-se falar de salário. Mas eu gosto porque não é uma função monótona, pelo curso que eu fiz, instrumentação, você fica bitolado a uma sala. Já na operação a cada turno você encontra uma coisa nova, é muito difícil encontrar as minhas funções iguais ao que eu deixei no dia anterior, mas é claro que tem as rotinas mas variam as situações de dosagens de aditivos por exemplo. Para os produtos não saírem dos parâmetros, você tem que variar 0 aditivo. Outra coisa é a vigilância dos equipamentos, bombas e preparo de soluções, hoje você faz uma quantidade de aditivos, amanhã já será outra". (OC5-13) 
Outros trabalhadores manifestaram discurso semelhante, com ênfase ao risco, relativização da tecnologia de segurança, porém com insatisfação com o trabalho. O sentimento de que o Pólo já se esgotou como possibilidade de um bom emprego, ao lado da manifestação de insatisfação com o trabalho, surgiu em 37,5\% dos operadores que tenderam a realçar os aspectos do esforço físico e mental e o desgaste no trabalho, enfatizando os riscos. Os baixos salários acentuam essa forma de ver o risco, ao lado do trabalho sindical de denúncias das condições de trabalho e saúde no Pólo Petroquímico de Camaçari. Os dados de doença ocupacional, a Campanha "Caça Benzeno" desencadeada pela CUT no ano de 1991 e as repercussões da morte de um médico do trabalho por leucopenia no ano de 1990, deixam sementes para que essa forma de representação do risco se torne preponderante no Pólo, aproximando os trabalhadores de campo aos da sala mais antigos e descontentes.

\section{Divisão de Manutenção}

Os trabalhadores da manutenção são, na grande maioria, do sexo masculino, predominando a faixa etária de 31 a 40 anos $(48,6 \%)$. São, geralmente, de origem mais humilde que os dos demais setores, procedentes do interior do estado da Bahia e residentes nos subúrbios e de Salvador ou nos municípios vizinhos. São filhos de lavradores em 35,29\% dos casos, de trabalhadores da construção civil $(23,52 \%)$, de industriários $(23,52 \%)$, de comerciantes $(11,76 \%)$ e de funcionários públicos $(5,8 \%)$.

$\mathrm{O}$ início da vida laborativa é mais precoce nesse grupo: $18,75 \%$ começaram a trabalhar com menos de 10 anos de idade; $50 \%$ entre 10 e 14 anos; $12,5 \%$ entre 15 e 17 anos e $18,75 \%$ após os 18 anos. Cerca de $80 \%$ desses trabalhadores tinham experiência profissional anterior ao emprego atual, geralmente em empreiteiras. $\mathrm{O}$ acesso à empresa estudada se deu de imediato à função, com ou sem evolução posterior. Somente no setor de instrumentação e eletricidade o acesso se deu na função de estagiário. Também nesse setor a força de trabalho é relativamente estável. Entre estes se encontra o maior percentual de baixa escolaridade (primeiro grau incompleto ou completo).

O saber nesse setor é mais fragmentado na multiplicidade de funções e o poder é mais facilmente concentrado nas mãos da gerência. A relação dos supervisores de manutenção com os trabalhadores segue eixos semelhantes à operação, no que se refere ao paternalismo autoritário. Nota-se, contudo, que o sentimento de pertencer a uma "grande família" encontra-se mais presente nesse setor.

Nesse grupo, observou-se uma distinção entre os "peões" da mecânica e montagem e os instrumentistas e eletricistas. Tal distinção ocorre em paralelo com os elementos que delineiam a identidade dos sujeitos e as suas formas de representação do risco. Esse é o único grupo onde surge a negação do risco, talvez devido à origem sócio-cultural dos seus membros, que os coloca em situação mais difícil para ter acesso à empresa e galgar melhores posições ao longo da vida laborativa, ou mesmo, para manter-se no emprego. Seguem-se algumas das formas de representação do risco identificadas:

\section{A) Negação do Risco com Ênfase à Tecnologia de Segurança, Submissão e Aceitação das Condições de Trabalho}

MA3 tem 47 anos, procedente do interior da Bahia, filho de lavrador. Iniciou a vida laborativa aos 10 anos de idade na lavoura, onde permaneceu até os 22 anos. Antes do atual emprego, trabalhou em diversas empreiteiras e após a décima empresa conseguiu com um amigo a colocação na empresa em estudo. Estudou, apenas, até o primeiro grau completo. Permanece na mesma função em que ingressou há 10 anos e 8 meses.

MA3 considera que o risco é provocado pelo próprio trabalhador e que, no seu trabalho pessoal, não existe risco, como podemos depreender do seu discurso:

"O risco, eu acho assim, a gente é quem provoca (...) Porque se vai pegar uma corda e amarrar em um lugar alto e tá vendo que a corda é fraca, então prá que vai se pendurar?" (MA3-21) 
"Não acho que há risco no meu trabalho, prá mim, meu trabalho é tranqüilo". (MA3-22)

O discurso de MA3 revela forte noção de acidente como ato inseguro, de responsabilidade do trabalhador.

"O maior risco aqui dentro é a pessoa prevê o serviço, observá o que vai fazê, trabaiá com atenção, se prepará com os material de segurança, daí em diante ele tá sem risco. Porque é o seguinte: a gente tá vendo que aí fora uma pedra aí vai quebrá, vai vir uma ponta e acidentá uma pessoa. Prá que ele vai fazê isso?" (MA3-24)

Embora reconheça o risco do trabalho, que se inicia ao sair de casa, a responsabilidade é retornada para o indíviduo que tem medo:

"Eu acho prá mim que desde quando a gente sai de dentro de casa, prá mim o risco já tá na cara... porque se nóis pega um ônibus que vem de lá prá cá temos um risco. Quando chegar aqui dentro tá o risco, mas o medo é quem faz o risco, o maior risco é o medo". (MA3-25)

Ao definir os locais de risco, torna a repor o risco ao indivíduo:

"Quase todos (os locais) são arriscados. A área de HCN também é um pouco meio arriscada e por isso ela é isolada também. Só pode entrar com a segurança e daí em diante o cara mesmo é quem provoca o risco. Se ele vê que tá vazando o produto ele não pode ir lá. Tem que olhá prá biruta e saber prá onde ele vai. Ele não pode correr prá dentro prá dizer que vai combater". (MA3-27)

MA3 assume o risco como de responsabilidade unicamente individual:

"Ah, minha irmã, agora eu faço tudo prá num me acidentá, num me prejudicá. Se eu vê o risco lá, eu não vou me aproximar dele porque se uma rede elétrica parte, enquanto não desliga, tem risco. Então eu não vou passar por perto. Eu tenho que me afastar dele. Tenho que fazer alguma coisa por mim, proque se eu não fizer... Se for de minha área o risco, eu mesmo vou cobrir ele, e se não, eu tenho que procurar quem cubra". (MA3-30)
Demonstra ter confiança na planta, pelo nível de responsabilidade que identifica nos operadores e administradores, mas confia especialmente em si próprio. Considera que a área toda é protegida.

OA3 procura seguir, à risca, as normas de segurança, considerando-se treinado para a função que exerce. Valoriza as normas, e os EPIs são, para ele, fonte de satisfação no trabalho.

"Eu acho uma coisa muito importante. Se a gente vai trabaiá numa fábrica dessas e não tivesse o EPI a gente não iria satisfeito de trabaiá contente. Mesmo sem o EPI acontece, que dirá sem o EPI". (MA3-40)

Em relação às normas de segurança, ele afirma:

"Ah! Eu acho legal. Eu dô valô as normas de segurança. Porque eu acho que elas cumpre o devê dela e pede prá gente também cumprir nosso devê". (MA3-41)

MA3 se reporta ao trabalho sem expressar sentimento de isatisfação, nem enfatizar motivo de satisfação. Apenas refere ser o trabalho, às vezes, pesado e que apesar disso gosta do que faz.

\section{B) Eufemização do Risco com Ênfase à Tecnologia de Segurança com Autovalorização e Desencanto com o Trabalho}

MD4 tem 24 anos, é procedente do interior da Bahia, filho de fazendeiro. Iniciou a vida laborativa aos 21 anos de idade, tendo na empresa em estudo o seu primeiro emprego. Ingressou na função de estagiário e, em dois anos, galgou a posição de Instrumentista II. Completou o segundo grau com curso de contabilidade e está cursando a Universidade.

Para MD4 o seu trabalho não é tão arriscado, e o mais importante é seguir as normas de segurança e estar consciente dos riscos. MD4 considera o seu trabalho, em si, de pouco risco, embora identifique nos outros setores, especialmente operação, riscos maiores.

Considera que a maioria das atividades é 
arriscada, mas responsabiliza os companheiros, principalmente da operação, por negligenciar as normas de segurança:

"Acho que a maioria é arriscada, mas a de maior... Tem uma atividade que eu acho que é arriscada mas a gente não tem dados. $O$ pessoal que trabalha com o catalisador. Ele é cancerígeno, o pessoal não se protege. $A$ utilização de EPI, máscara, óculos normalmente não usam, e o catalisador fica na pele, sendo também aspirado por via respiratória. Como não causa nada de imediato, eles não usam... Mas é o efeito cumulativo. É freqüente a pessoa dizer: 'ah! eu faço sem luva, eu faço sem óculos, sem máscara, não tem problema não...' Retirada de bomba, os mecânicos fazem sem usar a máscara, porque o cheiro dá prá aguentar. Aí dizem: 'ah, não vou usar máscara porque dá prá aguentar o cheiro'. É freqüente isso (...) abertura de câmara de instrumento, por exemplo. Normalmente para retirar 0 instrumento é bloqueado e descontaminado pela operação. Aí nesse processo é que pode ocorrer a negligência de não uso de máscara. Sabe que a concentração é baixa e que é suportável. Então fica a favor do vento, que não recebe muito produto. Aí nesse processo deve ser feito com máscara, luva e possa ser que alguém não usa." (MD4-24)

Afirma seguir as normas, regularmente, e ressalta o papel de cada um para evitar o acidente:

"O que tá no papel é interessante. Fora do papel tá mais em função de cada um, porque a segurança ele cobra, mas as pessoas são negligentes mesmo, as pessoas relaxam. Mas a maioria dos acidentes é causado por eles. Na prática mesmo tem que cada um cuidar de si. Agora acho interessante a empresa conscientizar todo o pessoal, para que ela mesma tome as medidas de precaução". (MD4-42)

"Tem que seguir todas as normas de segurança, até mais que você ache que deva, prá se proteger. Acho que é certo. Mas isso aí não resolve tudo. Você pode tá bem protegido mas não anula todos os riscos". (MD4-35)

MD4 confia na planta, mas sua confiança na equipe e nos equipamentos é, no entanto, relativa. Procura sempre conferir o que the foi passado, confirmar as informações e execução de serviços e confiar, principalmente, em si mesmo. Valoriza as Brigadas e ignora a existência da Cipa, embora considere que a empresa visa mais o patrimônio que a saúde do trabalhador, através dos treinamentos.

MD4 relata que saiu da escola técnica cheio de sonhos e vontade de se desenvolver e aprender.

"Durante o primeiro ano foi tudo bem, tava na fase de aprendizagem (...) Mas agora tô achando tudo muito limitado. $A$ empresa não se interessa em aperfeiçoar mais os técnicos que ele tem. (...) Não é um trabalho que você fique saturado dele, rotineiro... Varia bastante, você tem vários tipos de serviço...Mas chega um tempo que você tá familiarizado com tudo e se sente limitado". (MD4-13)

\section{Divisão de Laboratório}

O grupo de laboratoristas é de composição etária semelhante ao dos operadores: são cerca de $87 \%$ na faixa dos 21 a 40 anos. Nesse grupo, observa-se maior participação do sexo feminino (17\%). São operários oriundos da classe média de Salvador, onde reside a maior parte deles (83\%). São filhos de profissionais de nível médio (67\%) ou superior (33\%). Todos possuem escolaridade média, exceto uma com nível superior. Geralmente iniciaram a vida laborativa após os 18 anos de idade, mais tardiamente que os grupos anteriores.

Apenas $17 \%$ ingressaram na empresa como estagiários e $17 \%$ como office boy. Os demais ingressaram diretamente na função de analista. A maioria do grupo não teve outras experiências profissionais antes do emprego atual.

O conhecimento necessário para o desenvolvimento das tarefas é bastante centrado em métodos de análises químicas e técnicas de manipulação de amostras. O contato com a planta é pontual e o conhecimento do processo produtivo é de caráter mais teórico que prático. Este encontra-se concentrado nas mãos do engenheiro chefe, sendo a autonomia do trabalho do grupo bastante restrita. Sua autovalorização se 
dá pela via da confiabilidade que lhe é depositada pela gerência.

Esse grupo se apresenta como o mais homogêneo dos três estudados, talvez devido à sua atividade menos diversificada e por se tratar de um grupo menor na empresa (24 trabalhadores). Observa-se, como no grupo dos operadores, a ênfase ao risco e à tecnologia de segurança vinculadas à autovalorização, entre trabalhadores mais antigos na empresa que não galgaram postos de chefia ou supervisão, como vemos a seguir.

\section{Ênfase ao Risco com Relativização da Tecnologia de Segurança e Insatisfação com o Trabalho}

LA1 tem 33 anos, é procedente de Salvador, filha de eletricista. Iniciou a vida laborativa aos 21 anos, na empresa em estudo. Ingressou na empresa há doze anos na função de analista e, atualmente, é analista II. Fez curso universitário.

LA1 enfatiza o risco pela natureza das matérias-primas e produtos. Considera o trabalho no laboratório mais arriscado que qualquer outro na empresa, pelo manuseio direto com as substâncias.

Dentre as diversas atividades, LA1 elege a análise de HCN como a mais arriscada, tal como mencionada por esta:

"Porque o pessoal deve ficar tenso... Tem que entrar com equipamento de ar dirigido. Tudo se faz com satisfação mas quando se trata com HCN, o pessoal muda de cor, tem aquele medo. Ninguém gosta de fazer. O pessoal não gosta de ir na área, mas o pior é HCN". (LA1-24)

LA1 não só denuncia o medo dos outros ao contato com o HCN como enfatiza o seu próprio, talvez por ser do sexo feminino o que lhe permite admiti-lo mais francamente. Não consegue apontar um local protegido no trabalho e generaliza o risco da empresa ao Pólo:

\section{“(...) O Pólo é um local muito perigoso. $A$} gente tem que estar preparado no dia-a-dia, principalmente agora com essas empresas com mais de 10 anos. A gente tem que estar preparado mesmo!" (LA1-35)
Não confia na planta, nos equipamentos nem na equipe. Prefere manter-se em constante estado de alerta, observando a biruta e atenta a todos os sinais. Relata que já vivenciou vários vazamentos e que a segurança não avisava, só depois que telefonavam, reclamando do cheiro.

Para LA1 as normas e equipamentos de segurança são muito limitados e não merecem confiança, como menciona abaixo:

“Os EPIs que eles dão é só paliativo. Mas não resolve. Os filtros não suportam os ppm de um vazamento. Não se pode ficar tranqüilo, despreocupado porque tem os EPI... Porque já pegamos muito tipo de vazamento de ter que correr. Quando menos se espera acontece alguma coisa. No laboratório tem que abandonar... Muitas vezes já aconteceu isso. Geralmente na partida de alguma unidade ou falha de manobra do operador". (LA1-36)

Considera as normas excessivamente rigorosas, e que a segurança só olha o lado técnico das situações, e esquece do lado humano. Isso tem gerado insatisfação em participar das atividades de segurança.

LA1 diz gostar do seu trabalho pelo aspecto de se sentir valorizada na função que tem, e gratificada pela experiência e conhecimentos adquiridos.

Porém todo o seu discurso revela indignação com as condições de trabalho, especialmente no que se refere ao risco e à saúde, em torno do que existem grandes incertezas.

\section{CONSIDERAÇÕES FINAIS}

As representações do trabalho e dos riscos nos diferentes grupos apresentaram-se distintas. Embora a autovalorização, pelo saber ou pelo esforço, esteja presente, basicamente as diferenças se dão por três tendências discursivas: de satisfação com o trabalho, de conformismo ou de desencanto. Demonstram satisfação aqueles para quem o emprego significou uma grande conquista. Isso devido à posição alcançada dentro da empresa, que o nivela, do ponto de vista salarial, ao mercado de trabalho do profissional de nível superior que ele almejou um dia ter se tornado. Também pode decorrer da forma de acesso ao próprio emprego, para quem 
enfrentou grandes dificuldades no mercado de trabalho por uma condição sócio-cultural menos favorecida. $\mathrm{O}$ conformismo é encontrado naqueles para quem o trabalho na empresa, embora represente um desgaste e acompanhe-se de uma queda progressiva do valor monetário, ainda é a melhor opção. São, geralmente, trabalhadores mais velhos cuja mudança de emprego já se tornou quase impossível. A insatisfação observada refere-se, principalmente, às condições salariais que não compensam um trabalho de alta responsabilidade e riscos, ressaltando-se suas consequiências para a saúde.

Embora os trabalhadores acima revelem heterogeneidade nas representações do risco, eles estão unidos por uma questão comum. Esta questão é evidenciada pelo reconhecimento, de alguma forma, de que o risco está marcadamente presente em suas vidas laborativas. Mesmo aliviado ou controlado, o riscos impõem um modo de vida próprio, uma condição de trabalho particular. Estão unidos pelo consentimento do trabalho sob risco, numa condição em que as opções de sobrevivência tornam tal consentimento uma quase imposição. Num mercado de trabalho com poucas possibilidades de emprego, o Pólo representa uma solução para as aspirações de ascensão da classe operária, em que a opção é o trabalho sob risco ou enfrentar o desemprego.

Através de frases como "Prefiro morrer poluído do que morrer de pobreza" dita por um operador chefe, e "Pólo, tô fora", pichada num dos murais da empresa, os trabalhadores expressam o conflito em que vivem ao se submeterem ao trabalho sob riscos no Pólo Petroquímico de Camaçari.

Permanecer cúmplices desse processo ou não, depende de uma maior apropriação e reelaboração do saber, acerca dos reais limites da tecnologia e dos efeitos potenciais dos riscos sobre sua saúde, estes concretamente expressos nos casos de acidentes e doenças que ocorrem na empresa e no Pólo.

Contudo, esse saber permanece sob estreito controle da empresa, dificultando a coletivização das experiências e a ruptura e redefinição dos riscos.

\section{RESUMO}

RANGEL, M. L. Saúde do Trabalhador Identidade dos Sujeitos e Representações dos Riscos a Saúde na Indústria Petroquímica. Cad. Saúde Públ., Rio de Janeiro, 9 (3): 333-348, jul/set, 1993.

Este trabalho enfoca o papel da identidade sócio-cultural dos sujeitos na construção de distintas representações sociais dos riscos à saúde nos locais de trabalho. Os riscos são concebidos como construções sociais, que se fazem por referência à identidade dos sujeitos, vivendo relações de poder/saber, que se expressam em formas de controle e resistência no cotidiano de trabalho. Trata-se de um estudo de caso, realizado numa indústria do Pólo Petroquímico de Camaçari-Ba, que examinou como operadores, mantenedores e laboratoristas representam os riscos à saúde existentes no seu cotidiano fabril.

Palavras-Chave: Saúde Ocupacional; Representações Sociais em Saúde; Saúde do Trabalhador Petroquímico; Identidade e Saúde

\section{REFERÊNCIAS BIBLIOGRÁFICAS}

AGIER, M. \& CASTRO, N. A., 1989. Daqui a uns cinco anos, dar o meu grito de liberdade Projeto Operário e destinos pessoais entre trabalhadores e líderes da nova indústria de processo na Bahia. (Mimeo.)

AGIER, M. \& GUIMARÃES, A. S. A., 1990. Identidades em conflito: técnicos e peões na Petroquímica da Bahia. Revista Brasileira de Ciências Sociais, 5: 51-68.

BERGER, P. I. \& LUCKMANN, T., 1976. A Construção Social da Realidade. Petrópolis: Vozes.

BOURDIEU, P., 1988. La Distincion. Madrid: Taurus.

GUIMARÃES, A. S. A., 1990. A gestão do trabalho na indústria Petroquímica (a forma geral e a variante paternalista). Cadernos do Centro de Recursos Humanos, n. 12: 55-69.

GUIMARÃES, A. S. A. \& CASTRO, N. A., 1988. Espaços regionais de construção da identidade e a classe trabalhadora no Brasil pós-77. Cadernos do Centro de Recursos Humanos, n. 12: 33-54. 
HIRATA, H., 1984. Division Internationale, Division Sexuale du Travail et Santé. Anais do Seminaire Franco - Brasiliense "Emploi, Division du Travail, Division des Risques et Santé". Universidade de São Paulo, Brasil.

KNIGHTS, D. \& WILLMOTT, H., 1989. Power and subjectivity at work: from degradation to subjugation in social relacion. Sociology, 23: 535558.
SANSAULIEU, R., s/d. L'Identité et les relations de travail. (Mimeo.)

, 1977. L'identité au Travail. Paris: Press de la Fondation Nationale des Sciences Politiques.

TERSSAC, G. \& CORIAT, B., 1984. Micro-électronique et travail ouvrier dans les industries de process. Sociologie du Travail, n. 4: 384-397. 